(RESEARCH ARTICLE)

\title{
Efficiency increase by surface modification of gas turbine blade
}

\author{
Syed Mustafa Rahmani ${ }^{1}$, Md. Fakhruddin H.N. ${ }^{1,}{ }^{*}$, Syed Yasear ${ }^{2}$ and Md. Asadullah ${ }^{1}$ \\ ${ }^{1}$ Methodist College of Engineering \& Technology, Abids Hyderabad Telangana State-1_India \\ ${ }^{2}$ Muffakham Jah College of Engineering and Technology, Banjara Hills, Hyderabad, Telangana-34_India
}

Publication history: Received on 17 February 2020; revised on 10 March 2020; accepted on 12 March 2020

Article DOI: https://doi.org/10.30574/gjeta.2020.2.3.0010

\begin{abstract}
Thermal barrier coatings (TBC's) are used to provide both thermal insulation and oxidation protection to high temperature components within gas turbines. The development of turbines for power generation and aviation has led to designs where the operation conditions exceed the upper limits of most conventional engineering materials. As a result, there has been a drive to improve thermal barrier coatings to allow the turbine to operate at higher temperatures for longer. The focus of this project is on thermal barrier coatings with lower conductivity and longer lifetime than those coatings used in industry today. The route taken to achieve these goals with APS TBC's has been twofold.
\end{abstract}

Firstly, an alternative stabilizer has been chosen for the zirconium oxide system in the form of yttria (Yttrium oxide, also known as yttria, is Y203. It is an air-stable, white solid substance. Yttrium oxide is used as a common starting material for both materials science as well as inorganic compounds). Secondly, variations in thickness of coating. The focus of the work has therefore been to characterize their lifetime and thermal properties when produced in a complete TBC system.

In earlier work yttria stabilized zirconia was used only for a particular thickness value. In this work different values of thickness are used for topcoat and characterization of this coated material is determined. While small at room temperature and in the as produced state; the influence becomes more pronounced at high temperatures and with longer thermal exposure time. The thermal barrier coated specimen of varying thickness was tested at both steady and transient conditions. There were many parameters being evaluated like hardness, surface roughness, microstructure and temperature gradient and stress distributions in the specimen. The temperature gradient was determined both under steady state and transient conditions experimentally as well as computationally using ANSYS V17.

Keywords: Thermal barrier coating; Yttrium oxide; Hardness; Surface roughness; Microstructure; Temperature gradient and Stress distribution.

\section{Introduction}

Thermal Barrier Coatings are highly advanced material systems mostly applied to metallic surfaces, such as gas turbines or aero engine parts which operate at elevated temperatures [1]. TBC are ceramic coatings with very low thermal conductivity that reduce the alloy surface temperature by insulating it from hot gas [4]. Thermal barrier coatings (TBCs) are applied to jet turbine blades to protect them from the high temperature gases leaving the combustion chamber and to increase the efficiency of the engine [5]. The temperature in the combustion chamber is about $2000^{\circ} \mathrm{C}$ and, after mixing with cooling air, the temperature of the gases reaching the turbine is $1250^{\circ} \mathrm{C}$, whereas the nickel super alloy used in the blades melts at $1427^{\circ} \mathrm{C}[3]$.

\footnotetext{
* Corresponding author: Md. Fakhruddin H.N.
} 
The purpose of TBCs is to insulate components from large and prolonged heat loads by using thermally insulating materials [3]. Thermal barrier coatings also reduce the amount of cooling air required [4].

\section{Preparation of specimen}

Available Forms of nickel Inconel 718 alloy are Wire, mesh, rod, bar, tube, pipe, sheet, plate, foil, strip, flanges. We took a rod of Inconel alloy and made into pieces of diameter $30 \mathrm{~mm}$ and depth $3 \mathrm{~mm}$.

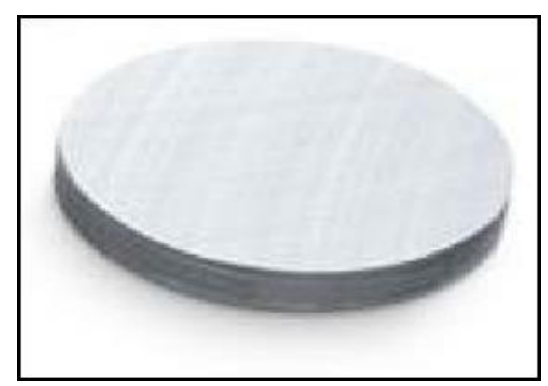

Figure 1 uncoated alloy

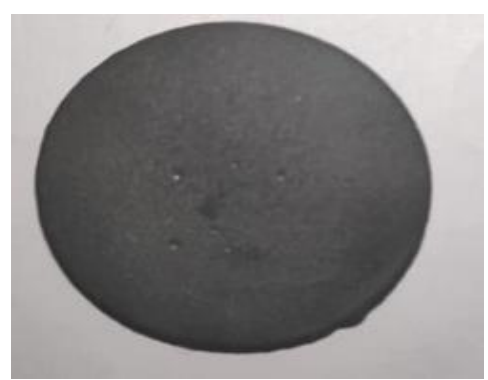

Figure 2 Yttria stabilized coated specimen

\section{Coating of specimen}

Coating of a specimen is to be done to resist it from corrosion and to increase life of turbine blade with a ceramic which has low thermal conductivity till now yttria is found to have lower thermal conductivity [2].

\section{Experimental investigation}

Nickel Super alloy (Nickel Inconel 718) 12 specimens, ease and economy with which INCONEL alloy 718 can be fabricated, combined with good tensile, fatigue, creep, and rupture strength, have resulted in its use in a wide range of applications. Examples of these are components for liquid fueled rockets, rings, casings and various formed sheet metal parts for aircraft and land-based gas turbine engines, and cryogenic tankage. It is also used for fasteners and instrumentation parts [6].

INCONEL alloy 718 has excellent corrosion resistance. Because of its strength, INCONEL alloy 718 is more resistant than most materials to deformation during hot forming. INCONEL alloy 718 can be readily machined, but its high strength and work- hardening characteristics must be considered in the selection and use of proper tool materials and design, operating speeds, and coolants. Inconel 718 has good resistance to oxidation and corrosion at temperatures in the alloy's useful strength range in atmospheres encountered in jet engines and gas turbine operations. Thermal Conductivity $15.04 \mathrm{~W} / \mathrm{m}-\mathrm{k}$ [7].

Table 1 Properties of nickel Super alloy

\begin{tabular}{ll}
\hline Melting Range (OC) & $\mathbf{1 3 7 2 - 1 4 2 7}$ \\
\hline Density (kg/m3) & 8880 \\
Thermal conductivity (W/M-K) & 15.04 \\
Specific heat (J/kg-K) & 460 \\
Elastic modulus (Gpa) & 72 \\
\hline
\end{tabular}

\section{Available forms of Inconel}

Wire, mesh, rod, bar, tube, pipe, sheet, plate foil, strip, flanges 
Table 2 Typical chemical composition of Inconel 718

$\begin{array}{ll}\text { Element } & \text { Percentage } \\ \text { Carbon } & 0.08 \text { max } \\ \text { Manganese } & 0.35 \text { max } \\ \text { Phosphorus } & 0.015 \text { max } \\ \text { Sulfur } & 0.015 \text { max } \\ \text { Silicon } & 0.35 \text { max } \\ \text { Chromium } & 17-21 \\ \text { Nickel } & 50-55 \\ \text { Molybdenum } & 2.80-3.30 \\ \text { Columbium } & 4.75-5.50 \\ \text { Titanium } & 0.65-1.15 \\ \text { Aluminum } & 0.20-0.80 \\ \text { Cobalt } & 1.00 \text { max } \\ \text { Boron } & 0.006 \text { max } \\ \text { Copper } & 0.30 \text { max } \\ \text { Tantalum } & 0.05 \text { max } \\ \text { Iron } & \text { Balance }\end{array}$

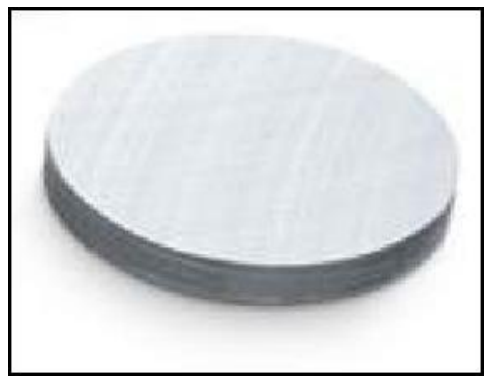

Figure 3 Composition of Coated Alloy

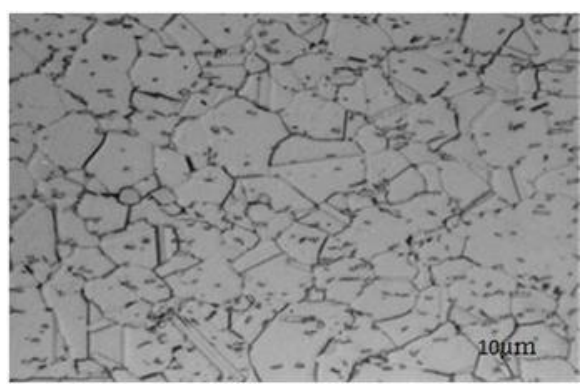

Figure 4 Micro structure of nickel Inconel 718 as observed in SEM (Scanning Electron Microscope) $\mu \mathrm{m}$

\subsection{Hardness}

Hardness is measure of resistance to localized plastic deformation induced by mechanical indentation or abrasion. The hardness of the specimen is checked by Rockwell hardness test and it is found to be 30Rc. 


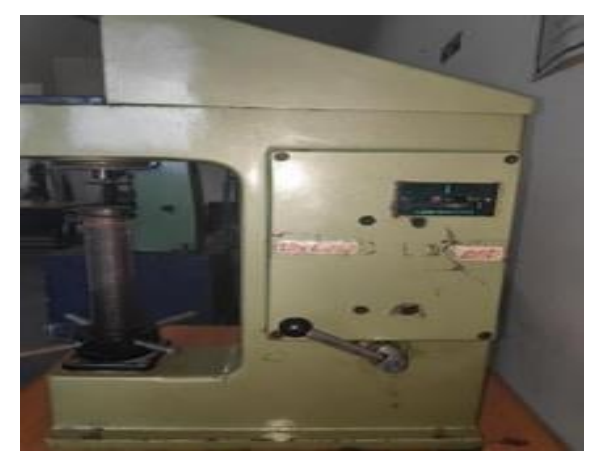

Figure 5 Rockwell hardness machine

\subsection{Roughness}

Roughness of specimen is measured by roughness tester TIME 3220. The roughness obtained is 2.08 for curved surface and 2.619 for flat surface.

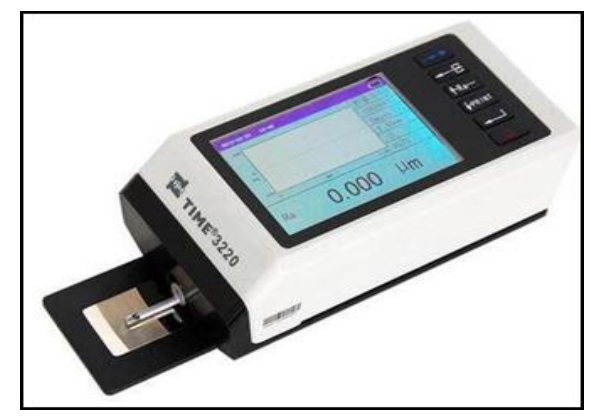

Figure 6 Time 3200 roughness tester

\section{Material and methods}

Coating of Inconel alloy is done to make alloy corrosion resistant increase life cycle of turbine blade. Coating is done on specimens at Spraymet Coating Industries, Bangalore. Coating is done to specimens are as listed below.

Coating of specimens is done by YSZ (yttria stabilized zirconia). Coating has two layers bond coat and top coat.

Table 3 Coating thickness of samples

\begin{tabular}{lc}
\hline Sample No. & Total thickness in microns \\
\hline 1 & 50 \\
2 & 100 \\
3 & 150 \\
4 & 200 \\
5 & 250 \\
6 & 300 \\
7 & 50 \\
8 & 100 \\
9 & 150 \\
10 & 200 \\
11 & 250 \\
12 & 300 \\
\hline
\end{tabular}




\section{Yttria-stabilized zirconia}

Yttria-stabilized zirconia (YSZ) is a ceramic in which the cubic crystal structure of zirconium dioxide is made stable at room temperature by an addition of yttrium oxide. These oxides are commonly called "zirconia" $\left(\mathrm{ZrO}_{2}\right)$ and "yttria" $\left(\mathrm{Y}_{2} \mathrm{O}_{3}\right)$. Pure zirconium dioxide undergoes a phase transformation from monoclinic (stable at room temperature) to tetragonal (at about $1173^{\circ} \mathrm{C}$ ) and then to cubic (at about $2370^{\circ} \mathrm{C}$ ), according to the scheme:

Monoclinic $\left(1173^{\circ} \mathrm{C}\right)$----tetragonal $\left(2370^{\circ} \mathrm{C}\right)$------cubic $\left(2690^{\circ} \mathrm{C}\right)$ melting point

Obtaining stable sintered zirconia ceramic products is difficult because of the large volume change accompanying the transition from tetragonal to monoclinic (about 5\%). Stabilization of the cubic polymorph of zirconia over wider range of temperatures is accomplished by substitution of some of the $\mathrm{Zr}^{4+}$ ions (ionic radius of $0.82 \AA$, too small for ideal lattice of fluorite characteristic for the tetragonal zirconia) in the crystal lattice with slightly larger ions, e.g., those of $\mathrm{Y}^{3+}$ (ionic radius of $0.96 \AA ̊$ ). The resulting doped zirconia materials are termed stabilized zirconia. Although 8-9 mol\% YSZ is known to not be completely stabilized in the pure cubic YSZ phase up to temperatures above $1000{ }^{\circ} \mathrm{C}[8]$.

\section{Thermal expansion coefficient}

The thermal expansion coefficient depends on the modification of zirconia as follows:

- $\quad$ Monoclinic: $7 * 10^{-6} / \mathrm{K}$

- Tetragonal: $12 * 10^{-6} / \mathrm{K}$

- $\mathrm{Y}_{2} \mathrm{O}_{3}$ stabilized: $10.5 * 10^{-6} / \mathrm{K}$

YSZ has a number of applications:

- For its hardness \& chemical inertness (e.g., tooth crowns).

- As a refractory (e.g., in jet engines).

- As a thermal barrier coating in gas turbines.
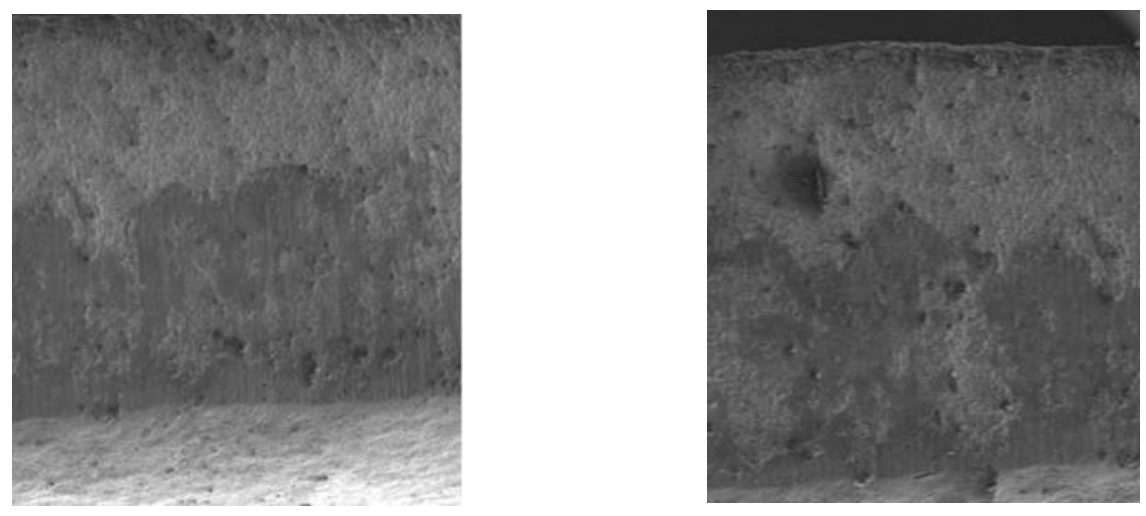

Figure 7 Microstructure of coated alloy \& its Side view 


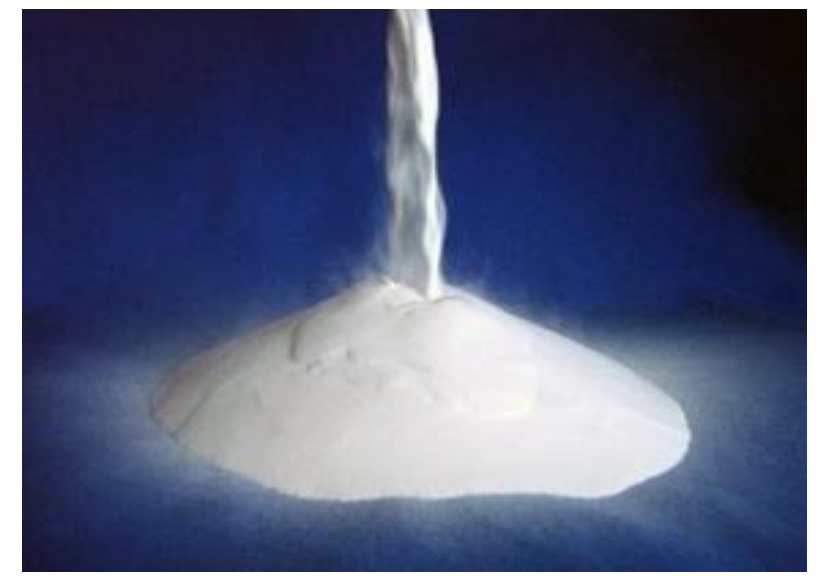

Figure 8 Yttria-stabilized zirconia 8\% powder

\subsection{Properties of Stabilized Zirconia}

- Strain tolerant

- Low thermal conductivity

- Ideal thermal expansion match

- High thermal stability

\subsection{Air plasma spraying}

The method utilizes an electrical arc ionizing Argon flowing through it and converting into hot plasma at a temperature of about $15,000^{\circ} \mathrm{F}\left(8,300{ }^{\circ} \mathrm{C}\right)$. The ceramic material in powdered form is injected into the plasma jet where the ceramic grains melt and move in the stream of the hot gas towards the substrate Surface. When the molten particles impact the substrate surface they solidify in form of splats.

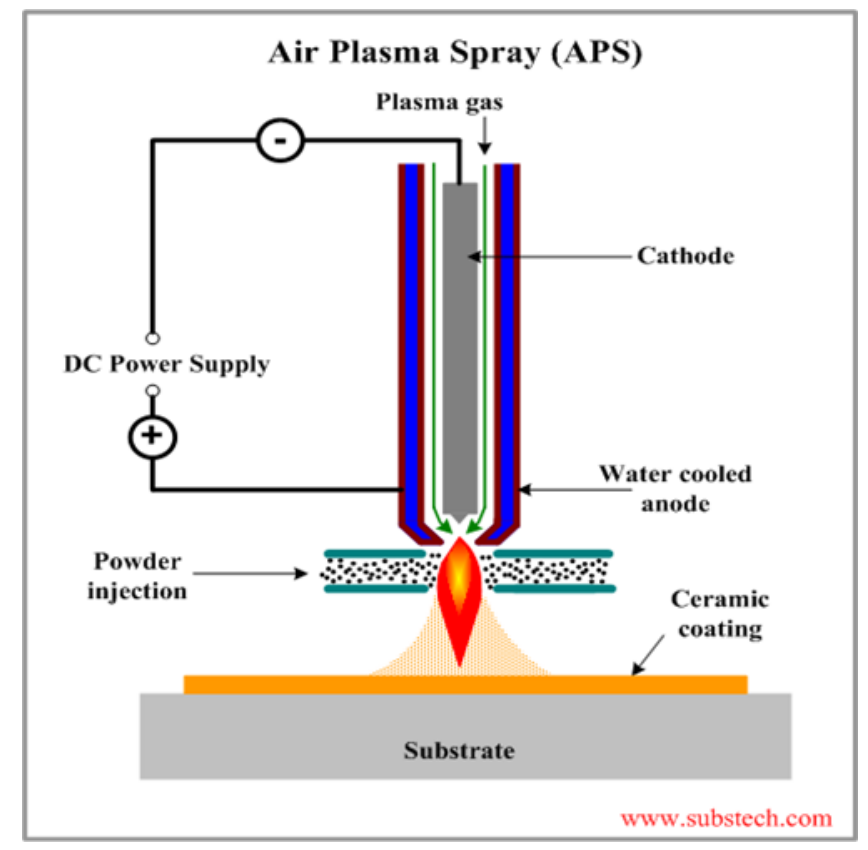

Figure 9 Air Plasma Spray

Microstructure is observed in SEM (Scanning Electron Microscope). Hardness of coated alloy by Rockwell harness test it is found to be $34 \mathrm{Rc}$. 


\section{Roughness of coated alloy}

Roughness of coated alloys measured by roughness tester TIME 3220 is as follows

Table 4 Roughness of coated alloys

\begin{tabular}{lll}
\hline Sl., No & Sample No. & Ra Values \\
\hline 1 & 1 & 10.13 \\
2 & 2 & 7.559 \\
3 & 3 & 10.48 \\
4 & 4 & 10.04 \\
5 & 5 & 10.41 \\
6 & 6 & 8.94 \\
7 & 7 & 8.75 \\
8 & 8 & 8.13 \\
9 & 9 & 9.033 \\
10 & 10 & 9.164 \\
11 & 11 & 11.14 \\
12 & 12 & 11.72 \\
\hline
\end{tabular}

\section{Heating of specimens}

Heating of a specimen is done up to $1300^{\circ} \mathrm{C}$ for every specimen and one specimen is heated up to failure of TBC. Heating is done from only one side of a specimen and cooling water is sprayed from another end of the specimen. The Temperature is measured by K-type Thermometer.

\section{Results and discussion}

\subsection{Temperature distribution of uncoated alloy}

Heat treatment of uncoated alloy is done by heating it on one side and cooling on other side to maintain large temperature gradient across its thickness. The obtained values of heat treatment are as listed below:

Heat treated values we got are of transient state whereas steady state analysis cannot be done practically so steady state analysis is done on Ansys. 


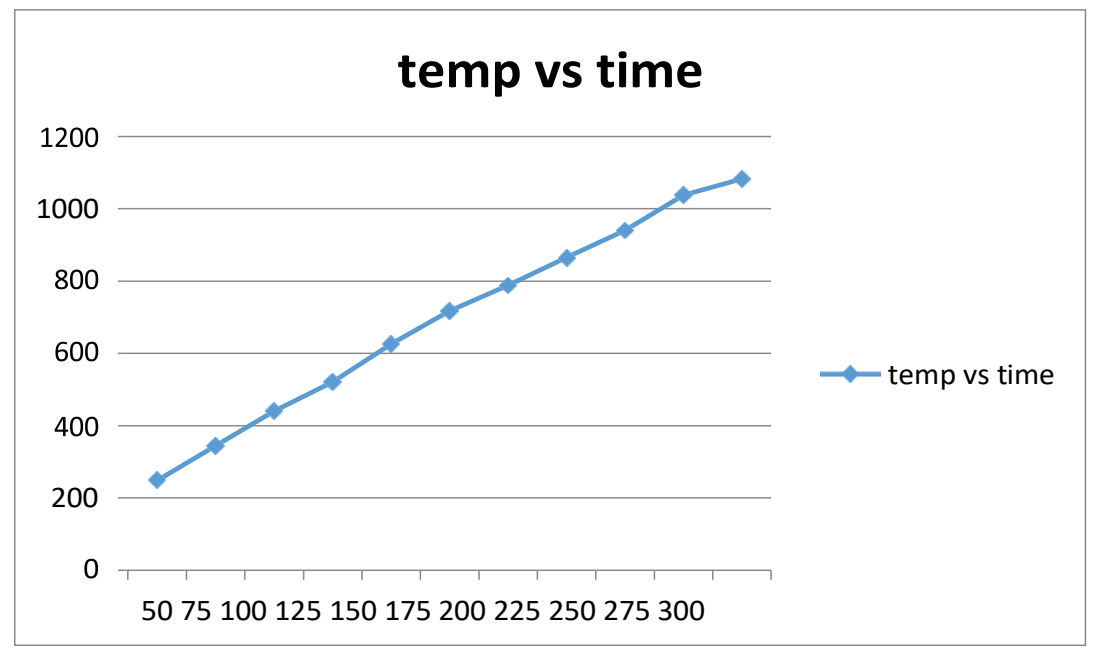

Figure 10 Graph of temperature values of back side

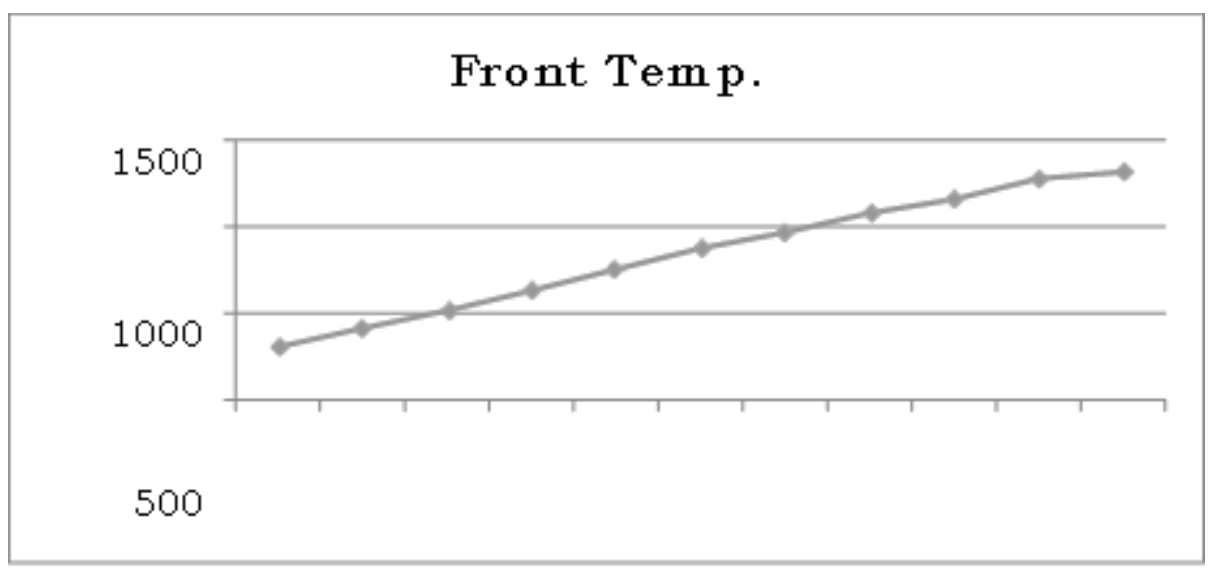

Figure 11 Graph of heated values of front s

Table 5 Properties of Inconel 718

\begin{tabular}{ll}
\hline Properties & Inconel 718 \\
\hline Density $(\mathrm{kg} / \mathrm{m} 3)$ & 8880 \\
Thermal Conductivity $\left(\mathrm{W} / \mathrm{M}^{*} \mathrm{~K}\right)$ & 15.04 \\
Specific heat $(\mathrm{J} / \mathrm{kg} \mathrm{K})$ & 460 \\
\hline
\end{tabular}

\subsection{Steady state analysis}

Thermal analysis under steady state conditions were done in ANSYS APDL V19 for the uncoated material having the following properties. 


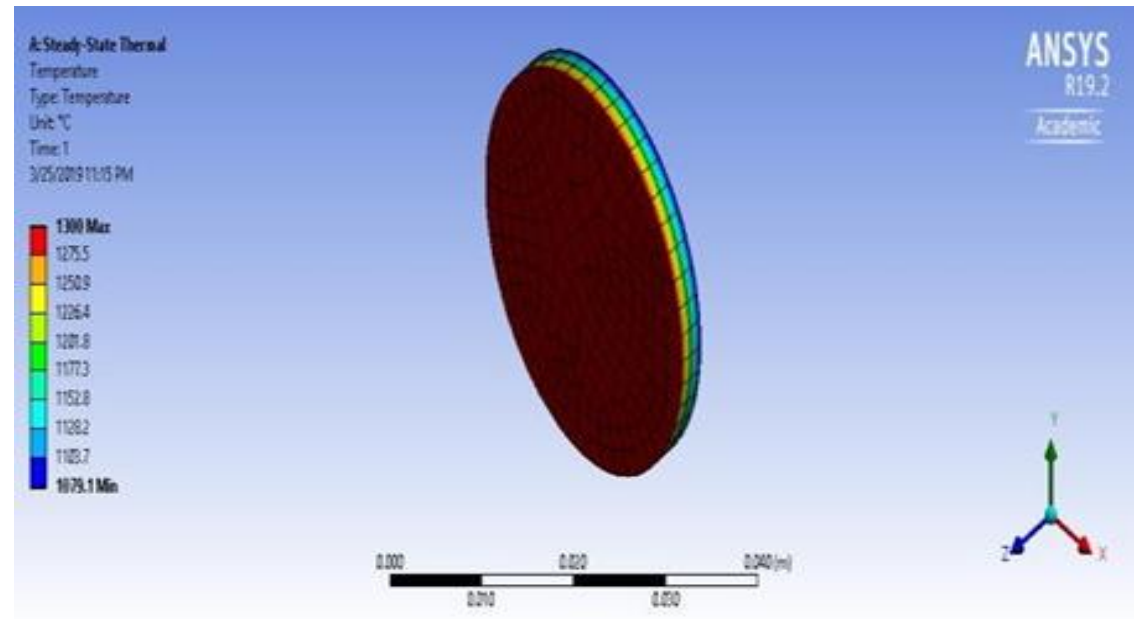

Figure 12 Uncoted alloy temperature analysis

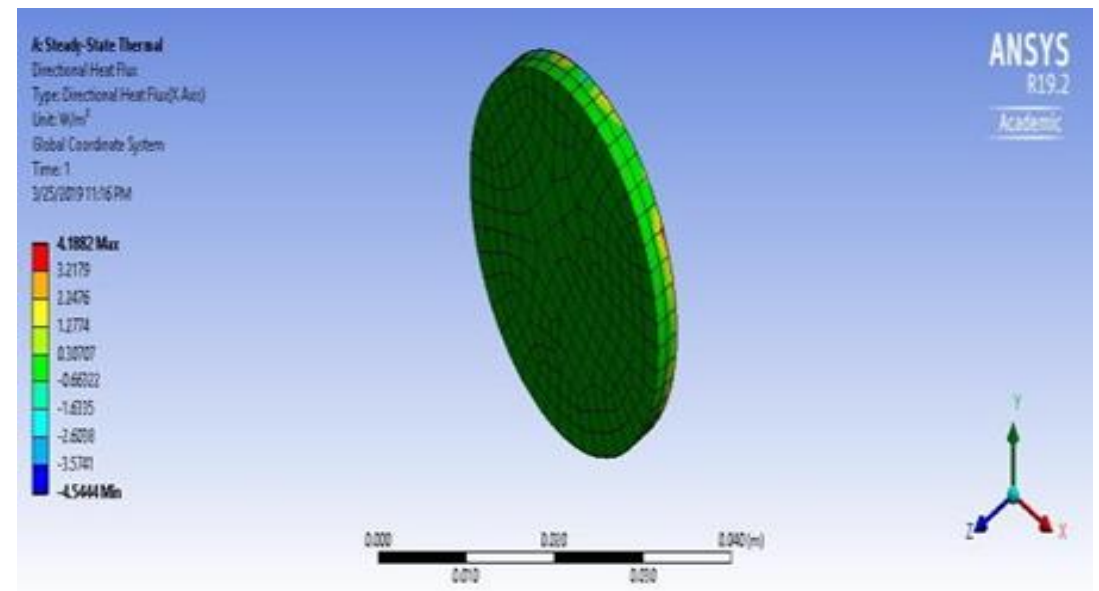

Figure 13 Uncoted alloy heat flow analysis

\section{Temperature distribution of coated alloy}

Temperature variation of coated alloy is obtained by heating it on one side and cooling on other side. The obtained values of heat treatment are:

Heat treated values we got are of transient state and steady state analysis cannot be done practically so steady state analysis is done on Ansys. 


\subsection{Transient state}

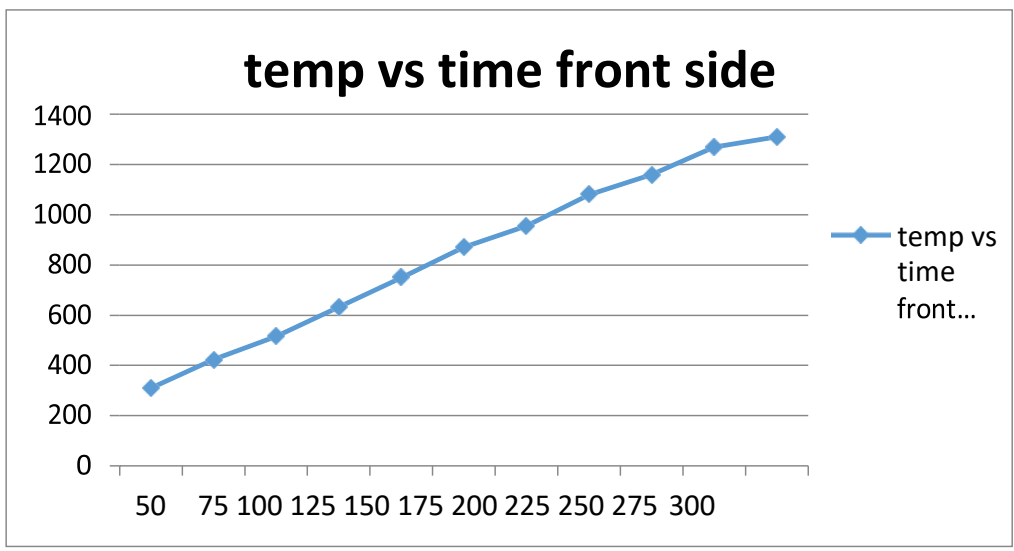

Figure 14 Graph of heated values of front side

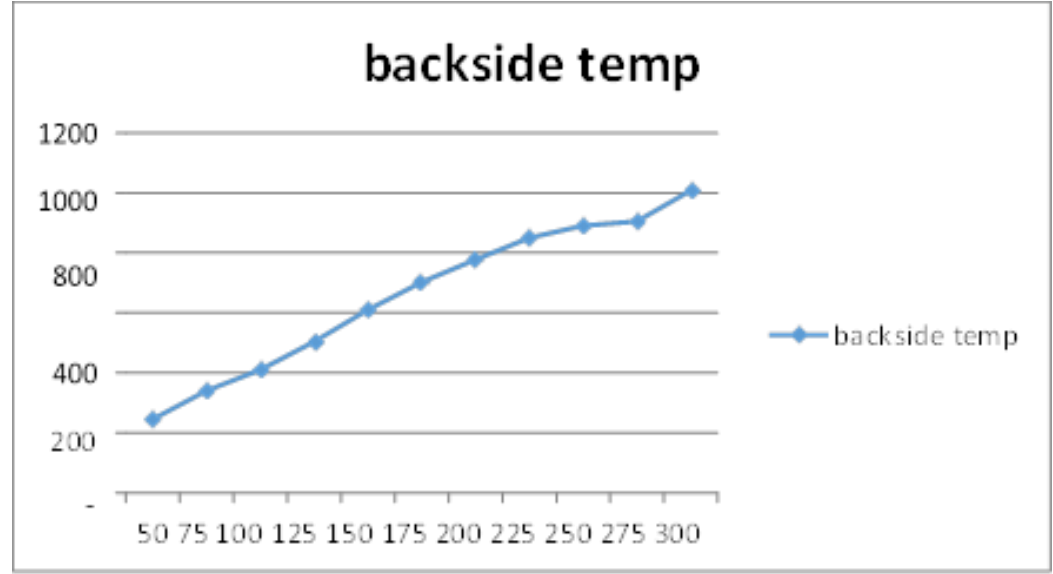

Figure 15 Graph of heated values of back side

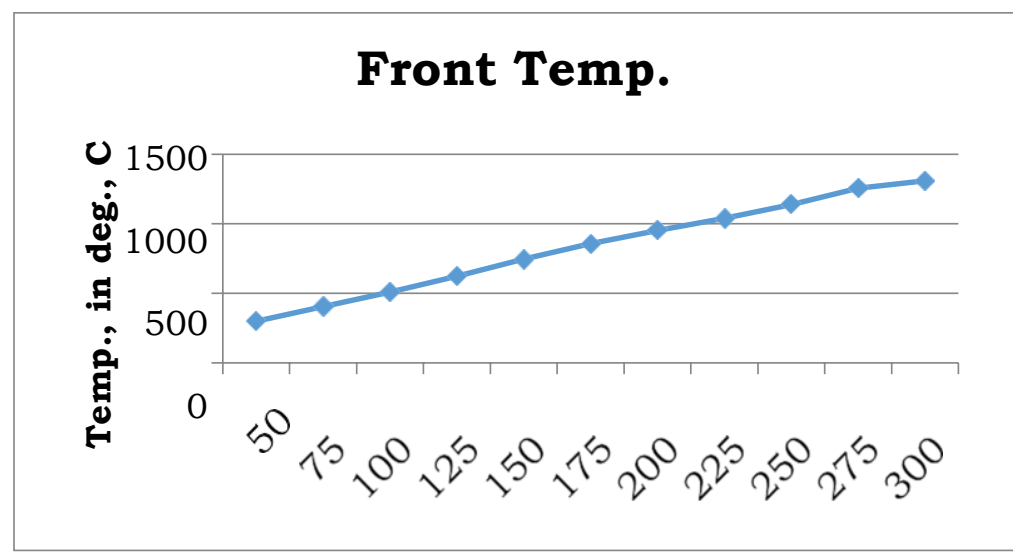

Figure 16 Graph of heated values of front side 


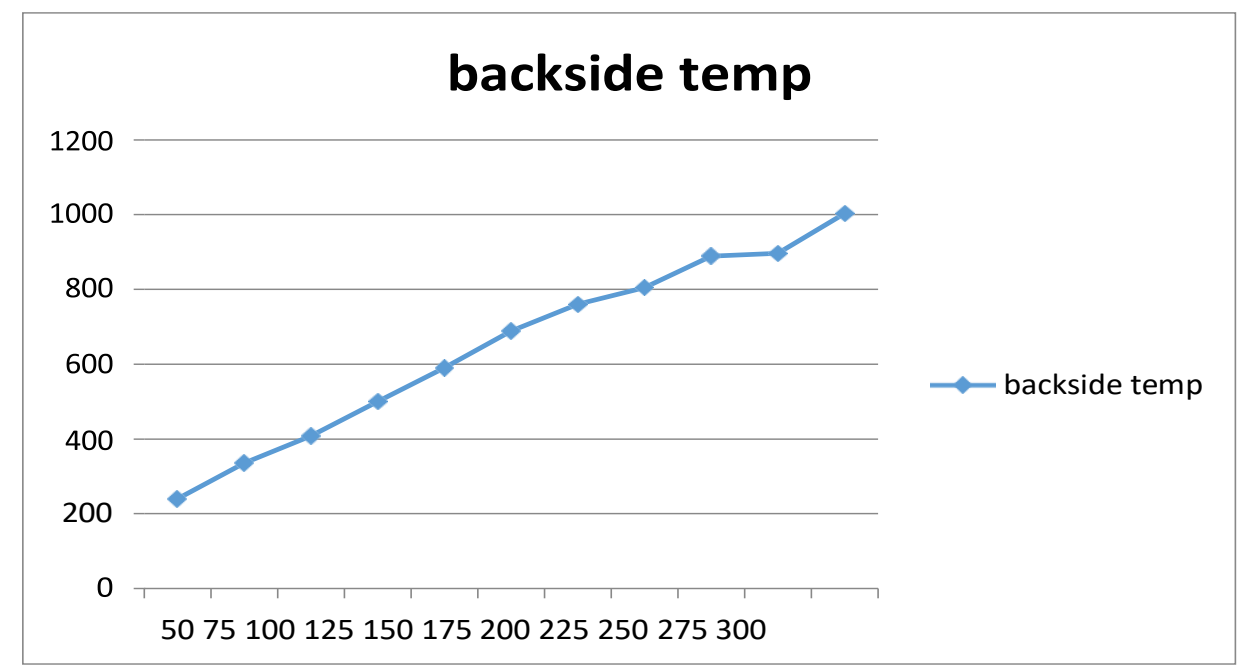

Figure 17 Graph of heated values of back side

\section{Steady State Analysis}

Thermal analysis under steady state conditions were done in ANSYS APDL- V17 for the coated material having the following properties.

\begin{tabular}{llll}
\hline Properties & Inconel 718 & NiCoCr Alloy & YSR \\
\hline Density $(\mathrm{kg} / \mathrm{m} 3)$ & 8880 & 7320 & 6037 \\
Thermal Conductivity $\left(\mathrm{W} / \mathrm{M}^{*} \mathrm{~K}\right)$ & 15.04 & 10.2 & 2.1 \\
Specific heat $(\mathrm{J} / \mathrm{kg} \mathrm{K})$ & 460 & 781 & 656 \\
\hline
\end{tabular}

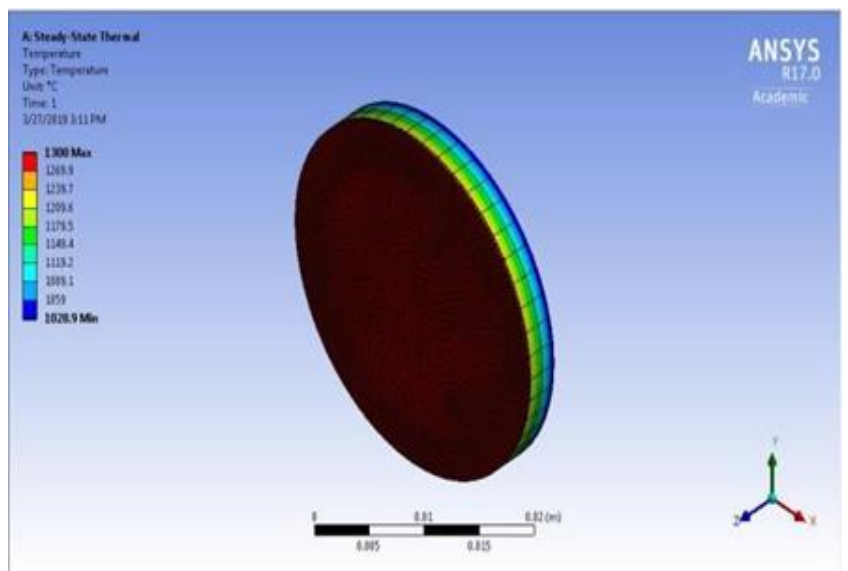

Figure 18 Coated alloy temperature analysis 
Syed et al. / Global Journal of Engineering and Technology Advances, 2020, 02(03), 022-034

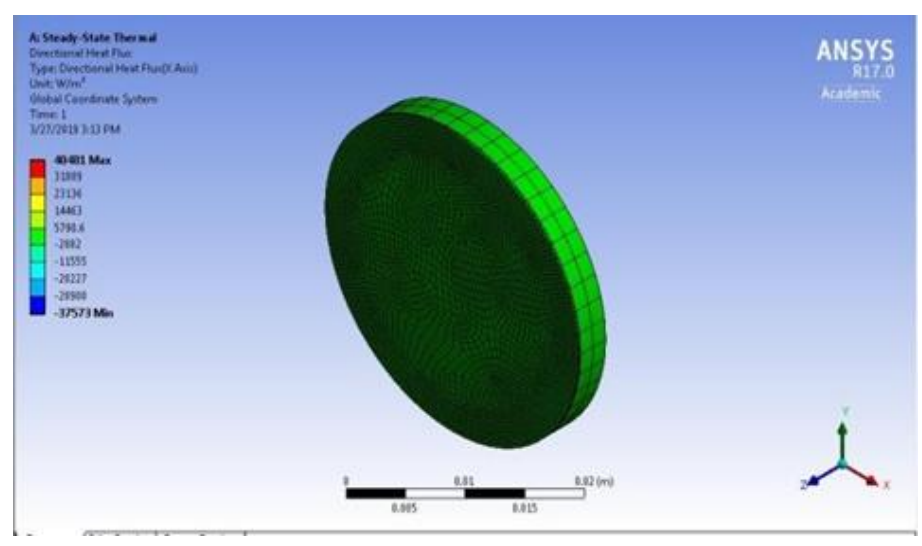

Figure 19 Coated alloy heat flow analysis

Table 6 Comparison between coated and uncoated alloys:

\begin{tabular}{lll}
\hline Time in Sec. & Uncoated & Coated \\
\hline 50 & 249 & 245 \\
75 & 344 & 340 \\
100 & 440 & 410 \\
125 & 521 & 503 \\
150 & 626 & 610 \\
175 & 717 & 702 \\
200 & 788 & 778 \\
225 & 865 & 850 \\
250 & 940 & 890 \\
275 & 1038 & 905 \\
300 & 1082 & 1008 \\
\hline
\end{tabular}

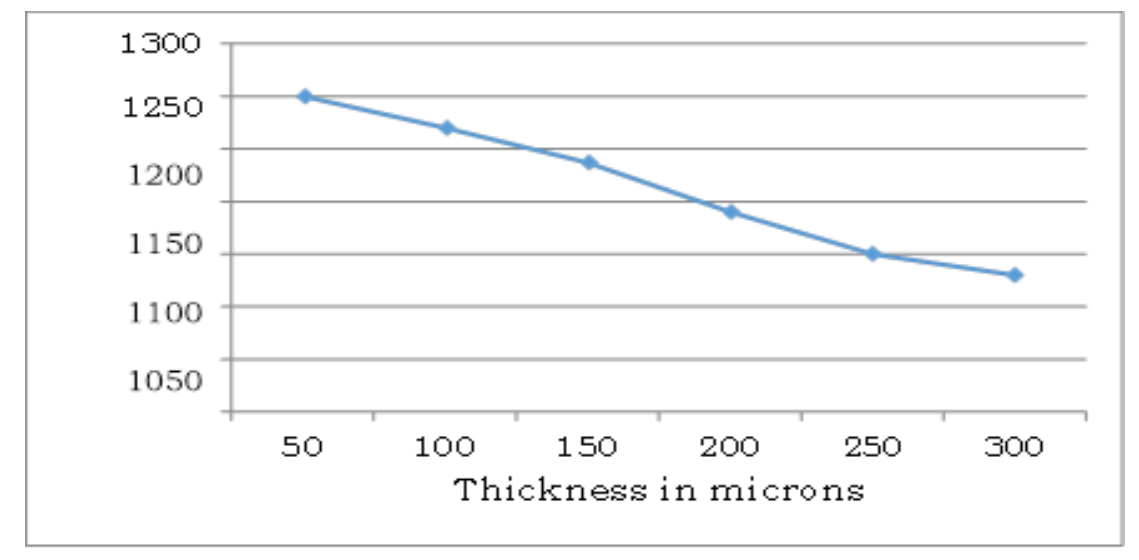

Figure 20 Thickness vs. temperature 


\section{Conclusion}

As the Temperature of gas coming from combustion chamber of gas turbine is $2000{ }^{\circ} \mathrm{C}$. After mixing it with cooling water its temperature reaches to $1250^{\circ} \mathrm{C}$. But super alloy temperature (melting point) is only $1427 \mathrm{C}$. As gas turbine goes on working it affects its efficiency. It is not possible by increasing air inlet temperature. So, we need to apply coating on nickel super alloy it increases the life cycle of a Gas turbine blade. The results obtained shows that the coating applied to the substrate has significant effect. There is considerable temperature drop across the thickness of the super alloy. The comparison of uncoated and coated alloy is shown in graph which clearly indicates the purpose of using the coated specimen. Both steady and unsteady heat transfer process is shown in the result. Since the coating thickness is very small in dimension therefore steady state condition is solved by computational method ANSYS in order to get better results.

\section{Compliance with ethical standards}

\section{Acknowledgments}

Thanks to Spraymet Coating Industries, Bangalore for providing experimental setup.

\section{Disclosure of conflict of interest}

"We have no conflict of interest to declare". This statement certify that all Authors have seen and approved the manuscript being submitted. We warrant that the article is the Authors' original work. We warrant that the article has not received prior publication and is not under consideration for publication elsewhere.

\section{References}

[1] International Journal of Innovative Research in Science Engineering and Technology 4(9). on Thermal Barrier Coating System.

[2] Some Recent Trends in Research and Technology of Advanced Thermal Barrier Coatings.

[3] A Review Paper on Thermal Barrier Coatings (TBC) to Improve the Efficiency of Gas Turbine Hiren Rana Protective coatings for gas turbines by Kang N Lee.

[4] Parametric Studies of Failure Mechanisms in Thermal Barrier Coatings by B. Srivatsha and D.K. Das 20(4), 899915.

[5] Microstructure and Mechanical properties of Inconel 718 Produced by SLM and subsequent heat treatment 651-653. (2015).

[6] RA Miller. (1995). Thermal Barrier Coating Workshop, NASA Lewis Research Center, Cleveland, OH, NASA Conference Publication 3312, 17-34.

[7] D Anson and DW Richerson. Progress in Ceramic Gas Turbine Development, Vol. 2. Edited by.

[8] M van Roode, M Ferber and DW. (2003). Richerson, ASME PRESS, New York, NY, 1-10.

\section{How to cite this article}

Syed Mustafa Rahmani, Dr. Md. Fakhruddin H.N., Syed Yasear and Md. Asadullah (2020). Efficiency increase by surface modification of gas turbine blade. Global Journal of Engineering and Technology Advances, 2(3), 22-34. 